Article

\title{
Potentiometric Zinc Ion Sensor Based on Honeycomb-Like NiO Nanostructures
}

\author{
Mazhar Ali Abbasi ${ }^{1, *}$, Zafar Hussain Ibupoto ${ }^{1}$, Mushtaque Hussain ${ }^{1}$, Yaqoob Khan ${ }^{2}$, \\ Azam Khan ${ }^{1}$, Omer Nur ${ }^{1}$ and Magnus Willander ${ }^{1}$ \\ 1 Physical Electronic and Nanotechnology Division, Department of Science and Technology, \\ Campus Norrköping, Linköping University, SE-60174 Norrköping, Sweden; \\ E-Mails: zafar.hussain.ibupoto@liu.se (Z.H.I.); mushtaque.hussain@liu.se (M.H.); \\ azam.khan@liu.se (A.K.); omer.nour@liu.se (O.N.); magnus.willander@liu.se (M.W.) \\ 2 Nanosciences and Catalysis Division, National Centre for Physics, Quaid-e-Azam University Campus, \\ 45320 Islamabad, Pakistan; E-Mail: yaqoob43@yahoo.com \\ * Author to whom correspondence should be addressed; E-Mail: mazhar.ali.abbasi@liu.se.
}

Received: 10 September 2012; in revised form: 1 November 2012 / Accepted: 6 November 2012 / Published: 9 November 2012

\begin{abstract}
In this study honeycomb-like $\mathrm{NiO}$ nanostructures were grown on nickel foam by a simple hydrothermal growth method. The $\mathrm{NiO}$ nanostructures were characterized by field emission electron microscopy (FESEM), high resolution transmission electron microscopy (HRTEM) and X-ray diffraction (XRD) techniques. The characterized NiO nanostructures were uniform, dense and polycrystalline in the crystal phase. In addition to this, the $\mathrm{NiO}$ nanostructures were used in the development of a zinc ion sensor electrode by functionalization with the highly selective zinc ion ionophore 12-crown-4. The developed zinc ion sensor electrode has shown a good linear potentiometric response for a wide range of zinc ion concentrations, ranging from $0.001 \mathrm{mM}$ to $100 \mathrm{mM}$, with sensitivity of $36 \mathrm{mV} /$ decade. The detection limit of the present zinc ion sensor was found to be $0.0005 \mathrm{mM}$ and it also displays a fast response time of less than $10 \mathrm{~s}$. The proposed zinc ion sensor electrode has also shown good reproducibility, repeatability, storage stability and selectivity. The zinc ion sensor based on the functionalized $\mathrm{NiO}$ nanostructures was also used as indicator electrode in potentiometric titrations and it has demonstrated an acceptable stoichiometric relationship for the determination of zinc ion in unknown samples. The NiO nanostructures-based zinc ion sensor has potential for analysing zinc ion in various industrial, clinical and other real samples.
\end{abstract}


Keywords: honeycomb $\mathrm{NiO}$ nanostructures; potentiometric response; ion selective electrode; selectivity; selective ionophore

\section{Introduction}

Zinc ion is the most abundant heavy metal ion in the human body and the quantity of zinc ion in serum is around $10 \mu \mathrm{M}$. Zinc ion is an important constituent of a number of enzymes such as carbonic anhydrase, matrix metalloproteinase [1], and also helps in the maintenance of structural characteristics of gene transcription proteins such as zinc finger proteins, etc. [2,3]. In addition to this, high levels of zinc ions are found present in the brain in chelatable form [4], in the pancreas [5], and spermatozoa [6]. The function of chelatable zinc ion is to govern the neuronal transmission in excitatory nerve terminals [4], inhibits apoptosis [7], and leads to neuronal injury under acute conditions [8], epilepsy [9] and transient global ischemia [10]. Zinc ions also stimulate the formation of $\alpha$-amyloid [11], which causes Alzheimer's disease. Excess of zinc ion can be toxic and pollute the environment as well as decrease the soil microbial activity [12,13]. Zinc ion is also found in food and agricultural wastes [14]. Because of the high quantity of zinc ion in the atmosphere, it can easily be ingested by the human body and may cause pulmonary manifestations, fevers, chills and gastroenteritis. Due to the above facts, it is very important to be able to detect trace quantities of zinc ion and abundant research on this topic is going on in many scientific fields such as medicinal and environmental analysis, etc. Many analytical techniques has been used for the determination of zinc ion, including UV-Vis spectroscopy [15], potentiometry [16] and flame atomic absorption spectrometry [17], inductively coupled plasma atomic emission spectrometry (ICPAES) [18] and fluorescence methods $[19,20]$. These techniques have some limitations due to the completely filled d-orbital of zinc ion, which results in an absence of suitable spectroscopic or magnetic signals. Beside these analytical tools, ion selective electrodes (ISEs) are comparatively simple, cheap and fast. Many zinc ion selective electrodes based on different ionophores have been reported [21-26]. Currently, different selective and sensitive polyvinyl chloride (PVC) membrane-based ISEs for different metal cations have been reported [27-31] and a zinc ion sensor based on functionalised $\mathrm{ZnO}$ nanorods has also been published [32]. Moreover, a Schiff's base has also been used for the detection of zinc ion [33].

Recently, the research trend towards nanomaterials is rapidly increasing due to their unique and excellent properties and versatile applications as compared to their bulk devices. The most distinguishing behaviour shown by nanostructures is their dimension-based excitation and emission. The electrical, optical, magnetic, and thermoelectric properties of solid-state functional materials can be controlled by the quantum confinement of electrons through the potential well of nanoscale based structures. Therefore, it is potentially important to grow such nanostructures which are very important for modern science and technology [34-37]. Among the various nanomaterials nickel oxide (NiO) is attractive to researchers due its tremendous properties such as wide band gap (3.6-4.0 eV) [38], magnetic, optical, and catalytic and electrochromic properties [39]. Nickel oxide nanostructures are of great interest for the development of electrochemical energy-storage tools due to their large specific 
surface area, rapid redox reactions and lowered diffusion path in the solid form. Nickel oxide is also used as magnetic storage material [40], optical active counter-electrode [41], in dye-sensitized solar cells [42], electrochromic films [43] and gas sensors [44,45]. Many methods have been reported for the synthesis of $\mathrm{NiO}$ nanostructures such as thermal evaporation [46], RF magnetron sputtering [47], and spray pyrolysis [48]. These growth methods have some limitations such as complex growth processes and the need for high growth temperatures. The size and morphology of the nanostructures is related to the type of technique used for their growth. By changing the growth parameters such as temperature, concentration, growth time, composition of sample solution using different amines, solvents and surfactants the nanostructures of different diameter, different morphologies can be obtained [49].

In the present research work, the hydrothermal growth method was selected for the growth of $\mathrm{NiO}$ nanostructures due to its versatility in growing nanostructures of various morphologies, ease, simplicity, environmental friendliness, cheapness and low temperature growth conditions [50]. Besides this, $\mathrm{NiO}$ nanostructures grown in the absence of organics at low temperature have also been reported [51]. We have grown honeycomb nanostructures of $\mathrm{NiO}$ on nickel foam without the use of any organic compound and the grown $\mathrm{NiO}$ nanostructures have been applied for the chemical sensing of zinc ion. This work provides an alternative approach for the further refinement of $\mathrm{NiO}$ nanostructures and their industry-based applications as well as use in chemical sensing.

\section{Materials and Methods}

\subsection{Materials}

Nickel sulphate heptahydrate $\left(\mathrm{NiSO}_{4} \cdot 7 \mathrm{H}_{2} \mathrm{O}\right), 25 \%$ ammonia $\left(\mathrm{NH}_{3}\right)$, zinc nitrate $\left[\mathrm{Zn}\left(\mathrm{NO}_{3}\right)_{2} \cdot 6 \mathrm{H}_{2} \mathrm{O}\right]$ ionophore (12-crown-4), sodium tetra phenyl borate (NaTPB), di-n-butyl-phthalate (DBP), tetrahydrofuran (THF) and polyvinyl chloride (PVC) were purchased from Sigma Aldrich Sweden (Stockholm, Sweden). All other chemicals used were of analytical grade.

\subsection{Fabrication of NiO Honey Comb Nanostructures}

The honeycomb-like $\mathrm{NiO}$ nanostructures were fabricated on nickel foam substrates using $\mathrm{NiSO}_{4} \cdot 7 \mathrm{H}_{2} \mathrm{O}$ and $\mathrm{NH}_{3}$ as primary chemical reactants. The nickel foam substrates were sonicated in an ultrasonic bath for 15 minutes using an ethanol solution. Then, the nickel foam substrates were cleaned with deionized water and dried in air. Afterwards the substrates were affixed in a Teflon sample holder and vertically dipped into a mixture of $0.1 \mathrm{M} \mathrm{NiSO}_{4} \cdot 7 \mathrm{H}_{2} \mathrm{O}$ and $0.1 \mathrm{M} \mathrm{NH}_{3}$ solutions prepared in deionized water. The sample solutions were kept in an oven at $90{ }^{\circ} \mathrm{C}$ for 7 hours. The role of $\mathrm{NH}_{3}$ in growth process is to act as a complexing reagent for nickel. When the growth time was completed then the substrates were taken out from the oven and a visible greenish colour type film was visible on the nickel foam, then the sample substrates were washed with deionized water and dried in an oven at $80{ }^{\circ} \mathrm{C}$ for 3 hours. After drying, some of the as-prepared nickel foam substrates were annealed in air at $500{ }^{\circ} \mathrm{C}$ in order to achieve $\mathrm{NiO}$ honeycomb nanostructures. 


\subsection{Functionalization of NiO Honey Comb Nanostructures with a Selective Zinc Ion Ionophore (12-Crown-4 Ether)}

The functionalization of the honeycomb-like $\mathrm{NiO}$ nanostructures with a selective zinc ion ionophore was performed as followed: the ingredients and amounts of each for the preparation of the membrane composition were as follows: 12-crown-4 (40 mg), NaTPB (40 mg), PVC (125 mg), and DBP (100 mg) in tetrahydrofuran $(12 \mathrm{~mL})$ [32]. Afterwards the $\mathrm{NiO}$ electrodes were dipped into membrane solution for 5 minutes using the direct adsorption method and dried at room temperature for 1 hour then the functionalized electrode were kept in a refrigerator overnight at $4{ }^{\circ} \mathrm{C}$.

\subsection{Potentiometric Measurements}

The potential measurements were carried out for the range of $0.0005 \mathrm{mM}$ to $100 \mathrm{mM}$ of zinc nitrate concentrations prepared in $1 \mathrm{mM}$ phosphate buffer solution of $\mathrm{pH} 7.3$ at room temperature. The functionalised $\mathrm{NiO}$ honeycomb-like nanostructures were used as working electrode and silver-silver chloride ( $\mathrm{Ag} / \mathrm{AgCl}$ as reference electrode. A model $744 \mathrm{pH}$-meter (Metrohm, Switzerland) was used for the potential measurements and a Keithley 2400 (Tektronix, Beaverton, OR, USA) source meter was used for the response time measurements.

\section{Results and Discussion}

\subsection{Characterisation of NiO Honeycomb Nanostructures}

The grown honeycomb-like nanostructures were characterised by FESEM, HRTEM, and XRD techniques. In Figure 1(a-d), low magnification FESEM images of the honeycomb-like nanostructures of $\mathrm{NiO}$ are shown, which demonstrated the attachment of $\mathrm{NiO}$ thin films on the nickel foam substrate. The honeycomb-like NiO nanostructures were clearly seen at high FESEM magnification and from this it can be seen that the grown $\mathrm{NiO}$ nanostructures are highly uniform and dense.

Figure 1. (a-d) FESEM images of honeycomb-like $\mathrm{NiO}$ nanostructures at different magnifications.
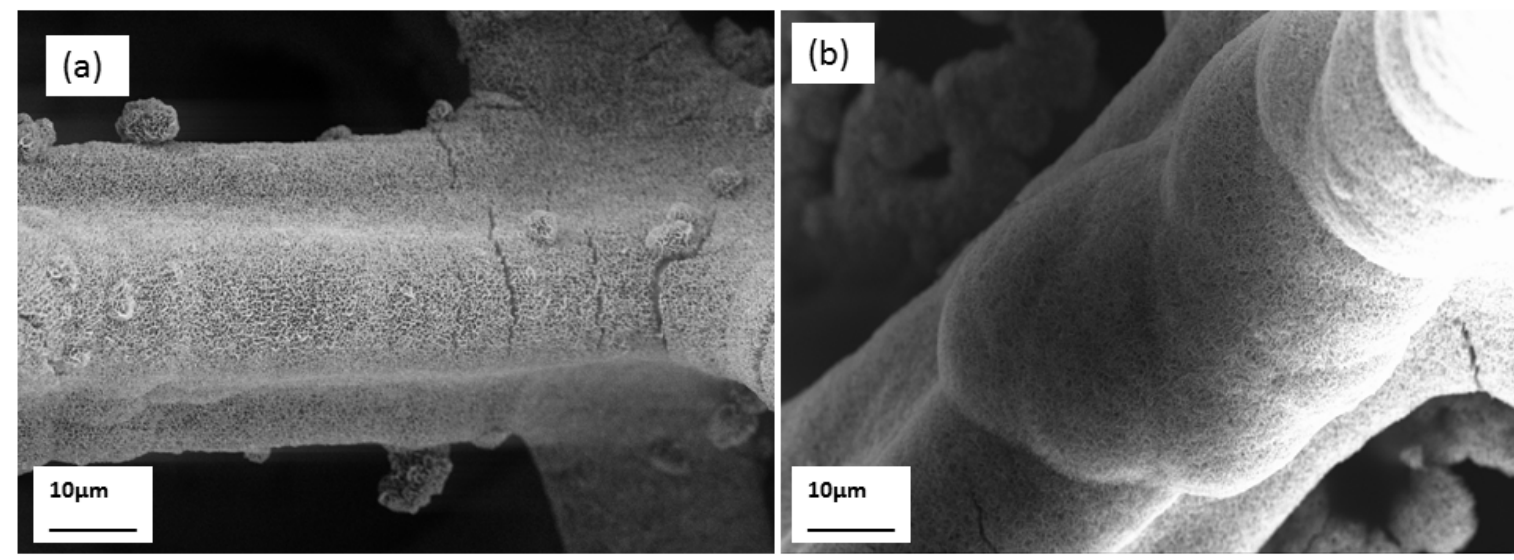
Figure 1. Cont.

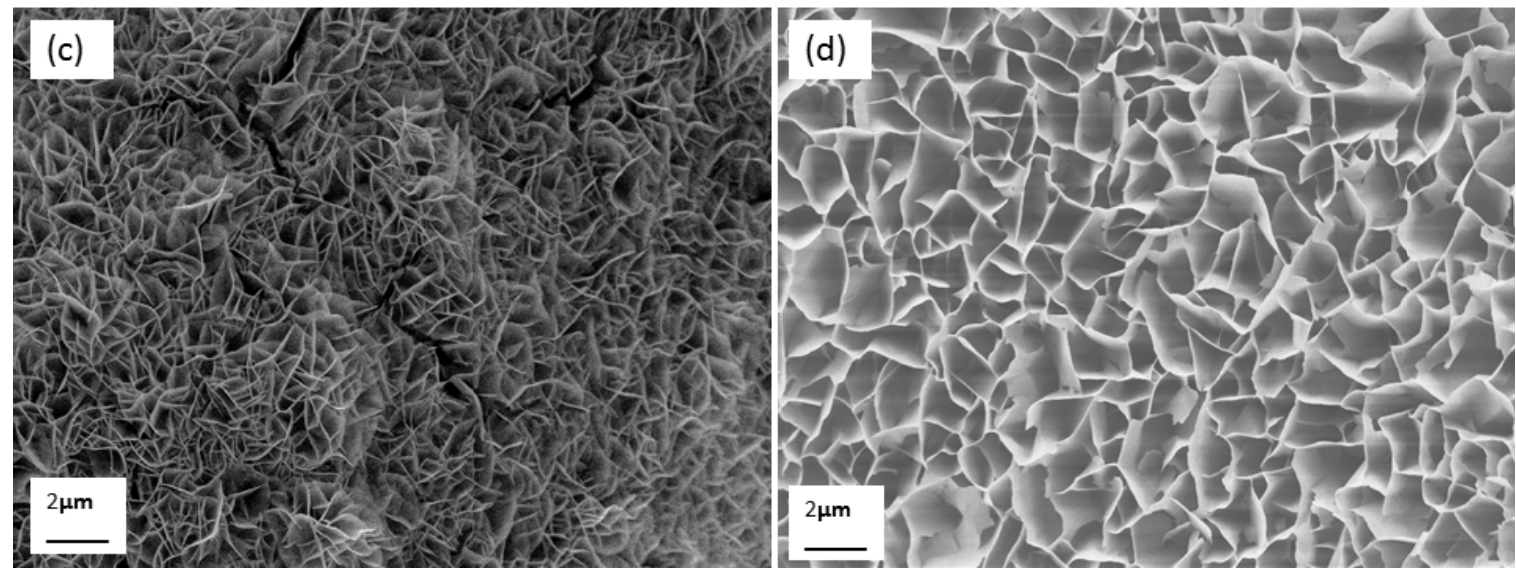

The x-ray diffraction study showed that the nickel oxide honeycomb nanostructures exhibited a face centred cubic phase crystalline structure as shown in Figure 2 and the pattern of XRD is supported by literature data (JCPDS NO. 47-1049).

Figure 2. (a-c) TEM images of $\mathrm{NiO}$ nanostructures.

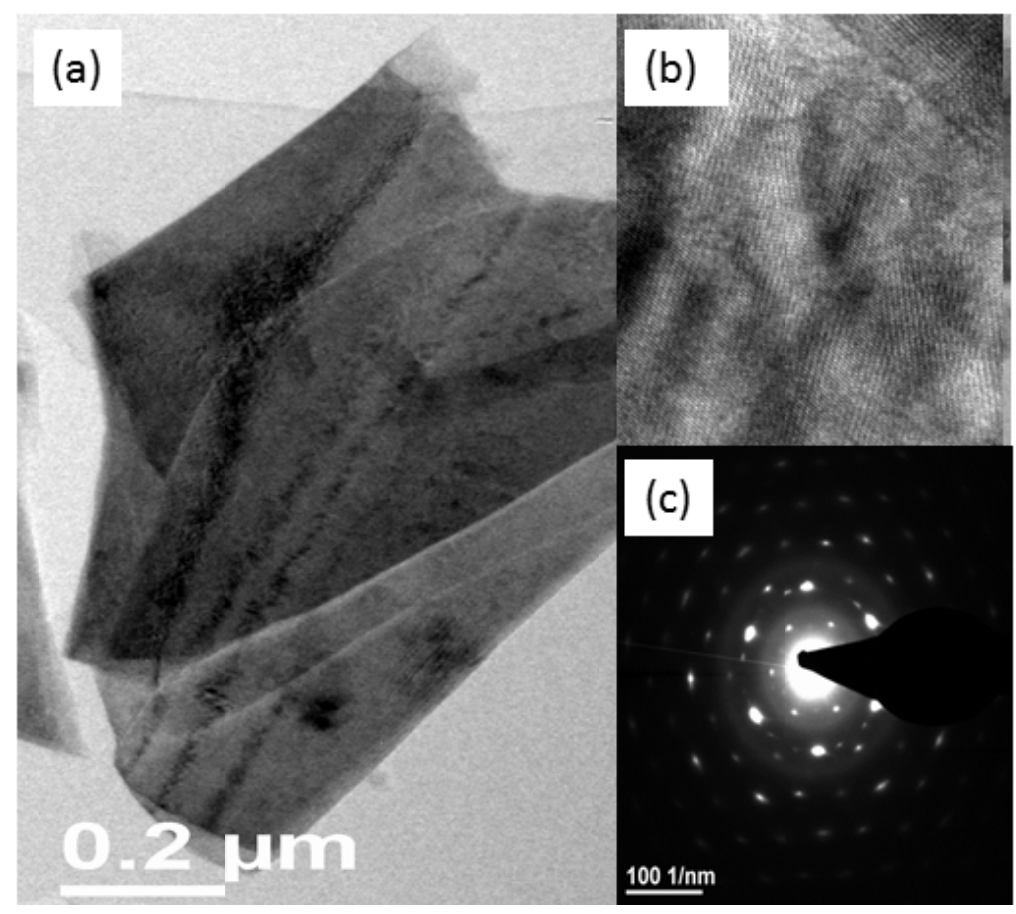

The transmission electron microscopy study revealed that the $\mathrm{NiO}$ honeycomb nanostructures possessed face centred cubic crystallinity with a space lattice of $0.21 \mathrm{~nm}$ for the (002) crystal plane of $\mathrm{NiO}$, as shown in Figure 3(a). In the selected area electron diffraction pattern (SAED, Figure 3(b)), it has been observed the results are almost consistent with the XRD patterns; therefore the honeycomb-like nanostructures of $\mathrm{NiO}$ are cubic in crystallinity with the presence of rings in the nanostructures described the nanoflakes nature of $\mathrm{NiO}$ as shown in Figure 3(c). The crystal size of $\mathrm{NiO}$ was calculated by XRD using Scherer's equation for 200 crystal plane and the obtained value for the crystal size is $62 \AA$. 
Figure 3. XRD pattern study of the $\mathrm{NiO}$ nanostructures.

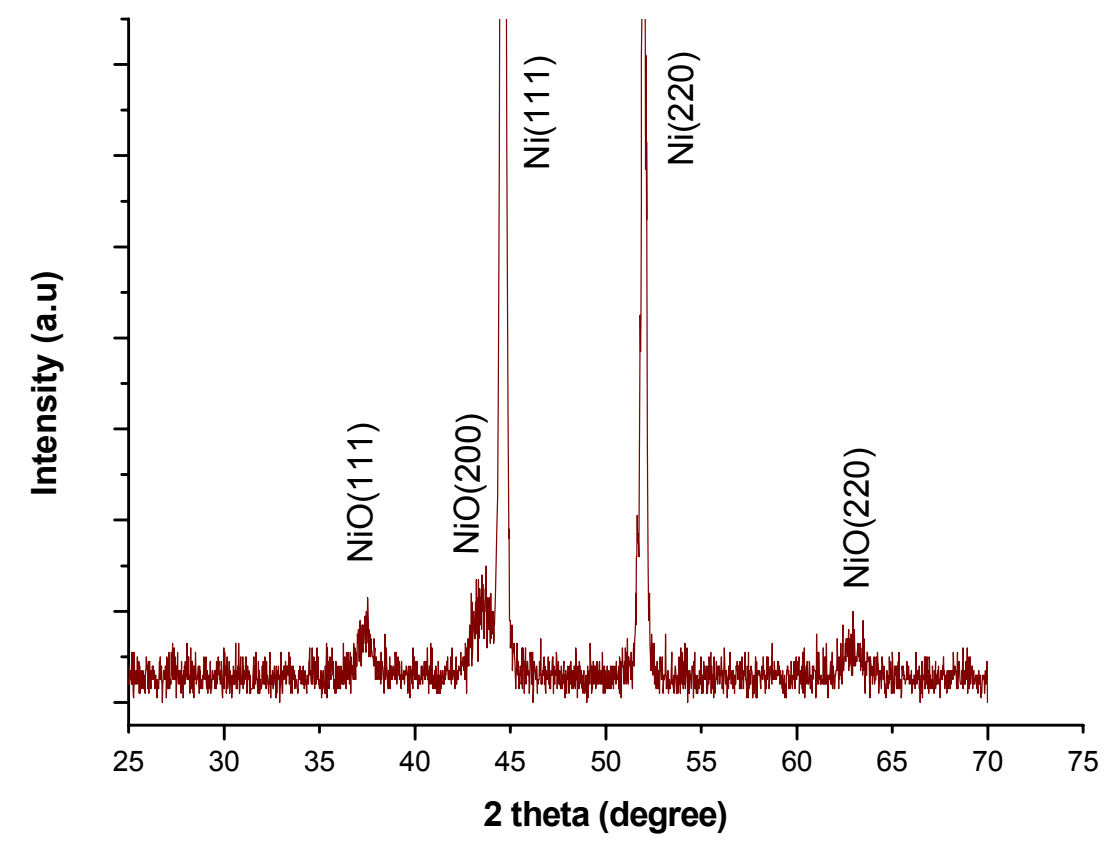

\subsection{Potentiometric Response Measurements of the Honeycomb-Like Functionalised}

$\mathrm{NiO}$ Nanostructures

The potentiometric response of the honeycomb-like functionalised NiO-based zinc ion selective electrode was measured for the zinc ions concentration range of 0.0005 to $100 \mathrm{mM}$. The sensor electrode detected $0.0005 \mathrm{mM}$ concentration of zinc ion, but it was out of the linear range. After the $0.0005 \mathrm{mM}$ concentration of zinc ions, the proposed sensor has shown a highly linear response for $0.001 \mathrm{mM}$ to $100 \mathrm{mM}$ concentrations of zinc ions, as shown in Figure 4.

Figure 4. Calibration graph of zinc ion sensor from $0.0005-100 \mathrm{mM}$ zinc nitrate concentrations.

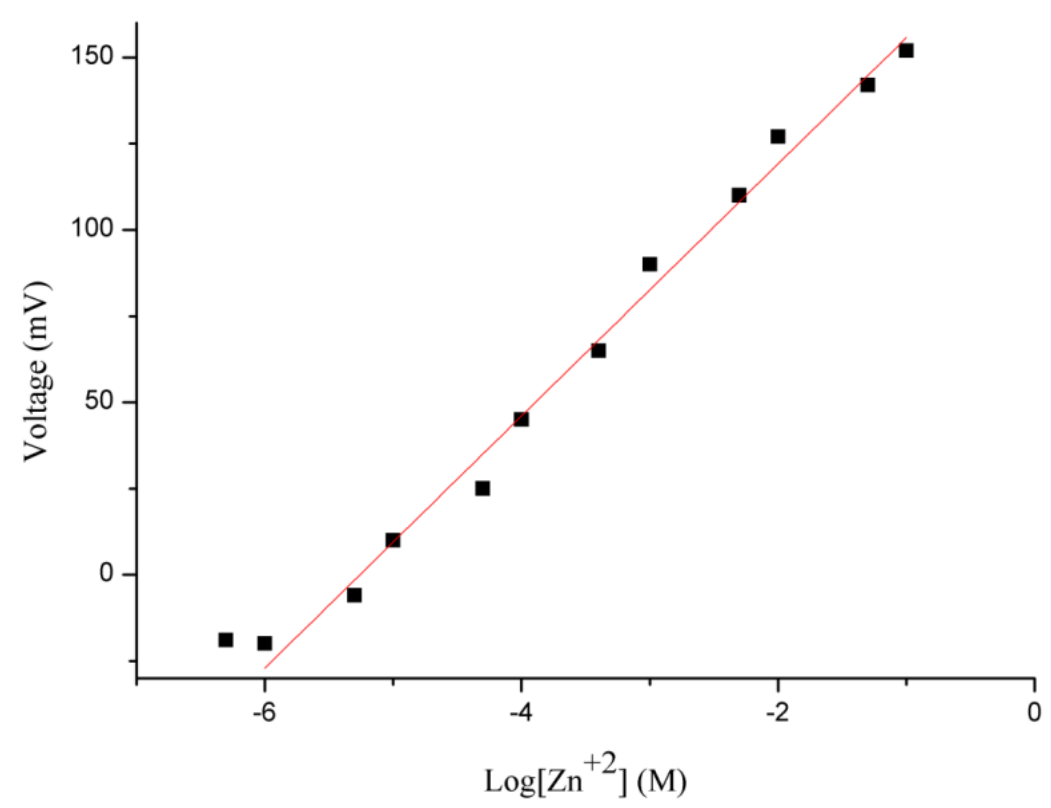


A sensitivity of $36 \mathrm{mV} /$ decade for the functionalised $\mathrm{NiO}$ nanostructures-based zinc ion sensor was observed, with a regression coefficient of $r^{2}=0.99$. This is due to the high surface provided by the honeycomb-like nanostructures for the attachment of the selective zinc ion ionophore and due to shortened diffusion path in the solid phase of the $\mathrm{NiO}$ nanostructures which might be responsible for the slightly higher slope value than the theoretical value. These two characteristics of the proposed sensor electrode confirmed its potential applicability for analytical purposes.

\subsection{Working Performance of the Honeycomb-Like Functionalised NiO Nanostructures-Based} Zinc Ion Selective Electrode

In this study, repeatability, reproducibility, and selectivity of the proposed ion selective electrode were examined. The repeatability of the ion selective electrode describes the response of a specific electrode which has been more than once under the same set of conditions. The functionalised NiO-based zinc ion selective electrode was tested for three consecutive days and it showed good repeatability with similar ranges of zinc ion detection, sensitivity and regression coefficient values as shown in Figure 5.

Figure 5. Repeatability of zinc ion sensor for $0.0005-100 \mathrm{mM}$ zinc nitrate concentrations.

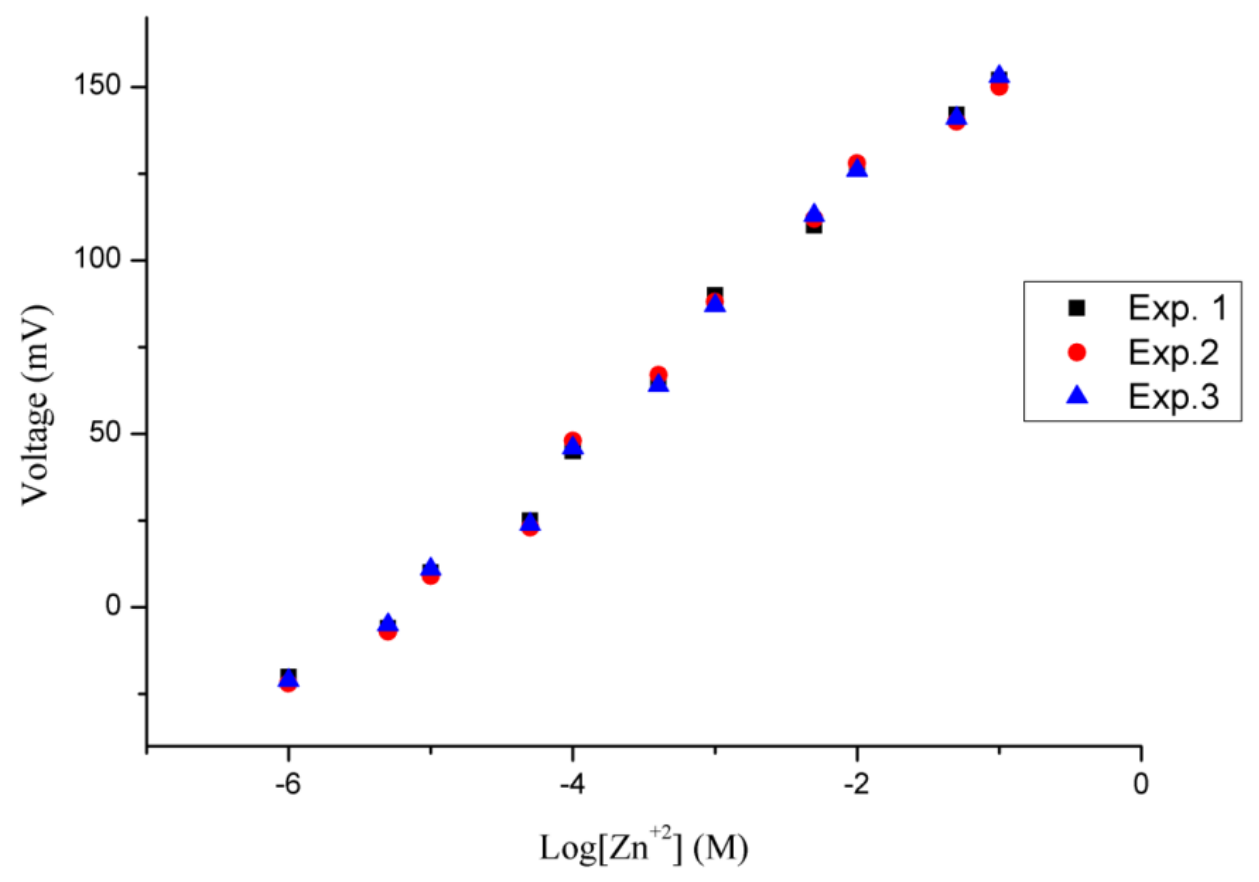

For reproducibility, seven independent ion selective electrodes based on the honey- comb-like nanostructures of $\mathrm{NiO}$ were functionalised under the same conditions. All these zinc ion selective electrodes were used in a $0.1 \mathrm{mM}$ solution of zinc nitrate electrolyte. It was observed that the proposed zinc ion selective sensor electrodes demonstrated high reproducibility with less than 5\% standard deviation, as shown in Figure 6. 
Figure 6. Reproducibility of zinc ion sensor in $0.1 \mathrm{mM}$ solution of zinc nitrate.

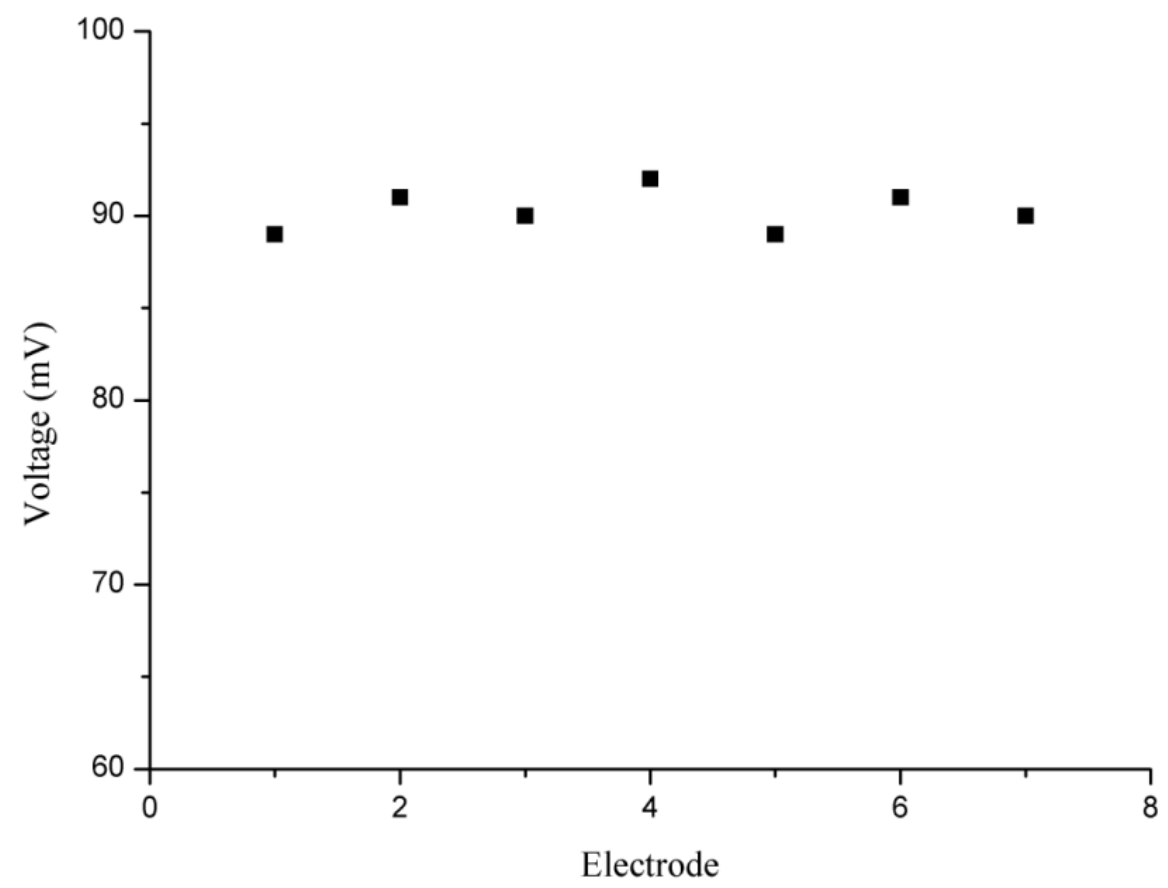

Selectivity of an ion selective sensor electrode is the fundamental parameter among all other parameters for the performance evaluation of an ion selective electrode. The separation solution method, which is recommended by IUPAC [52], was used for the study of the selectivity of the ion selective electrode by determination of the selectivity of coefficient values of both mono and divalent metal cations using $1 \mathrm{mM}$ solution of each interferent. The calculated selectivity coefficient values are given in Table 1. The determined selectivity coefficient values are fairly constant and this study revealed that the proposed ion selective electrode is highly selective towards zinc ion.

Table 1. Calculated selectivity values for different interferents.

\begin{tabular}{|c|c|c|}
\hline Interferent $\left(\mathbf{X}^{+\mathbf{Z}}\right)$ & Slope (mV/decade) & $\log \boldsymbol{K}_{\mathbf{Z n} \boldsymbol{n}^{+2}, \boldsymbol{X}^{+\mathbf{Z}}}^{\mathbf{p o t}}$ \\
\hline $\mathrm{K}^{+1}$ & 2.40 & -4.34 \\
$\mathrm{Co}^{+2}$ & 4.30 & -3.70 \\
$\mathrm{Mg}^{+2}$ & 5.2 & -4.71 \\
$\mathrm{Fe}^{+3}$ & 7.6 & -3.05 \\
$\mathrm{Na}^{+1}$ & 7.5 & -4.70 \\
$\mathrm{Ni}^{+2}$ & 8.1 & -4.72 \\
$\mathrm{Cu}^{+2}$ & 3.6 & -2.65 \\
\hline
\end{tabular}

\subsection{Influence of Temperature on the Potentiometric Response of the NiO Nanostructures-Based} Zinc Ion Sensor Electrode

The response of an ion selective electrode is also temperature dependent due to changes in the ionic mobility of target ions in solution. In this experiment, the effect of temperature on the response of the proposed electrode was observed from room temperature to $75^{\circ} \mathrm{C}$. 
Figure 7. (a) Influence of temperature of the output response of zinc ion sensor. (b) Study of response time. (c) Potentiometric titration curve in $10 \mathrm{mM}$ zinc nitrate solution.

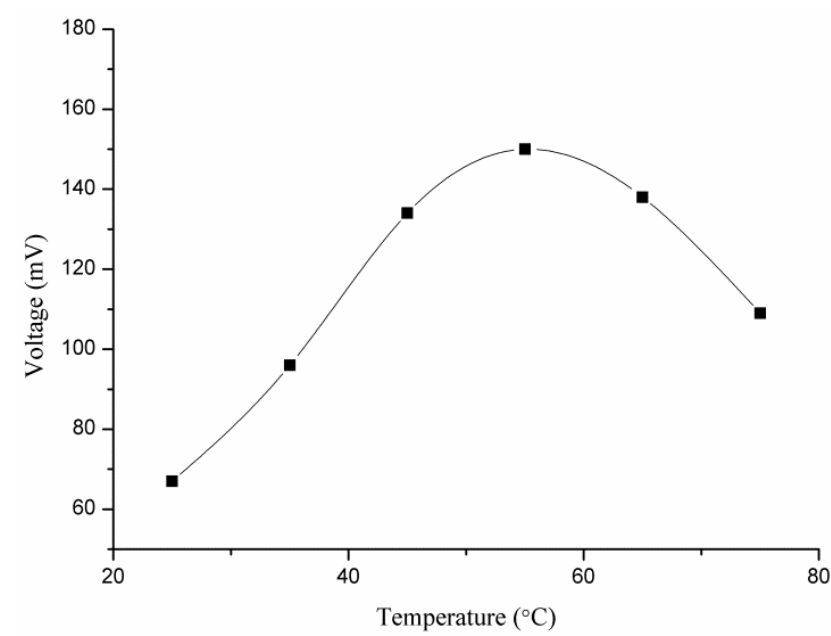

(a)

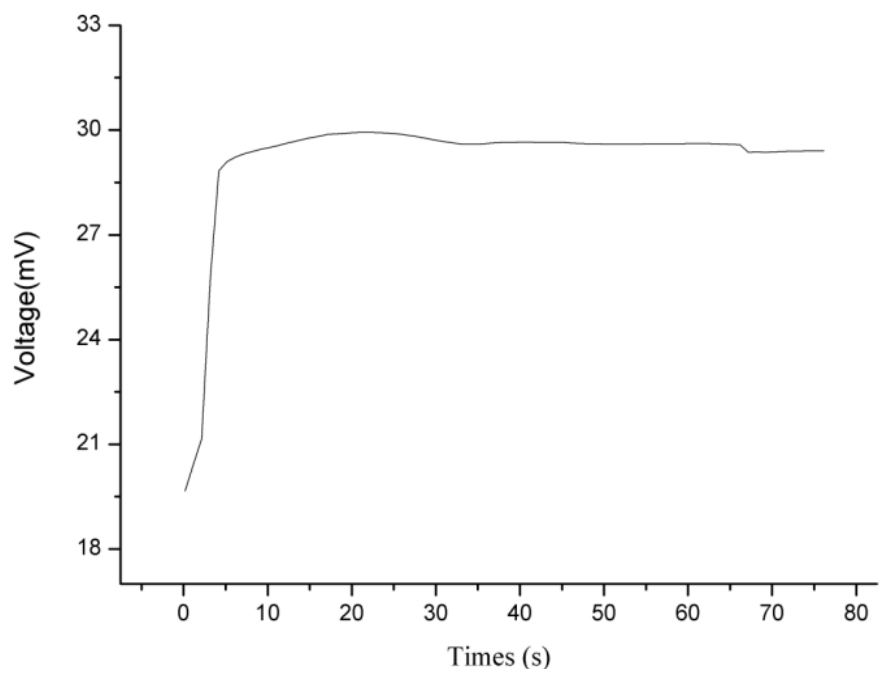

(b)

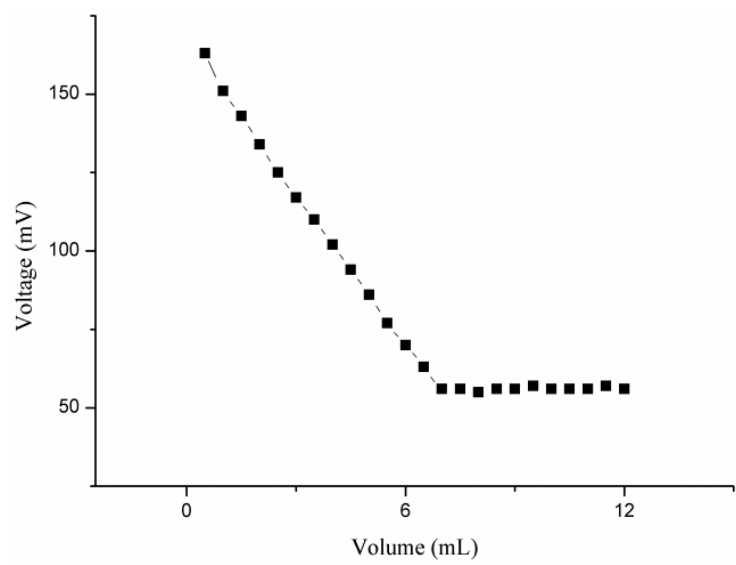

(c)

It can be inferred from the Figure 7(a), that the output response was increasing gradually up to $55{ }^{\circ} \mathrm{C}$ due to the increase in the mobility of zinc(II) ion, but above $55{ }^{\circ} \mathrm{C}$ the response trend was 
increasing due to possible detachment of ionophore membrane from the surface of the honeycomb-like nanostructures of $\mathrm{NiO}$ and also at higher temperature the analyte ions suffered from self-resistance in the solution. Moreover, the proposed zinc ion sensor has shown response time of less than $10 \mathrm{~s}$, as shown in Figure 7(b).

\subsection{Analytical Application of the NiO Nanostructures-Based Zinc(II) Ion Selective Electrode}

The functionalized $\mathrm{NiO}$ nanostructures-based ion selective electrode was used as indicator electrode for the potentiometric titration of $70 \mathrm{~mL}$ of $10 \mathrm{mM}$ zinc(II) ions against $100 \mathrm{mM}$ ethylenediaminetetraacetate solution [21] as shown in Figure 7(c). It can be seen from Figure 7(c) that with addition of EDTA the response of ion selective electrode was decreasing due to complex formation among zinc (II) ions and EDTA molecules, but at $7 \mathrm{~mL}$ a sharp intersection point was observed, which shows a good stoichiometric relationship for the determination of zinc ion concentration in unknown samples. Table 2 shows a comparison of the proposed zinc ion sensor based on the functionalised $\mathrm{NiO}$ honeycomb-like nanostructures with reported zinc ion sensors. The performance of the present zinc ion sensor is better than that of the reported zinc ion sensors due to the three dimensional network of $\mathrm{NiO}$ nanostructures and enhanced electrochemical properties of $\mathrm{NiO}$ in nanodimensional form.

Table 2. The comprative study of present zinc ion sensor with the reported zinc ion sensors.

\begin{tabular}{|c|c|c|c|c|}
\hline S. No & Concentration Range & $\begin{array}{c}\text { Slope sensitivity } \\
\text { (mV/decade) }\end{array}$ & $\begin{array}{c}\text { Response time } \\
\text { (Seconds) }\end{array}$ & Reference \\
\hline $\mathbf{1}$ & $0.006-100 \mathrm{mM}$ & 29.0 & 12 & {$[24]$} \\
$\mathbf{2}$ & $0.01-100 \mathrm{mM}$ & 35.0 & 5 & {$[32]$} \\
$\mathbf{3}$ & $0.013-100 \mathrm{mM}$ & 30.0 & 10 & {$[53]$} \\
$\mathbf{4}$ & $0.5-100 \mathrm{mM}$ & 33.0 & $20-25$ & {$[54]$} \\
$\mathbf{5}$ & $0.005-100 \mathrm{mM}$ & 29.7 & 8 & {$[55]$} \\
$\mathbf{6}$ & $0.001-100 \mathrm{mM}$ & 36.0 & Less than 10 & this work \\
\hline
\end{tabular}

\section{Conclusions}

In this work, honeycomb-like nanostructures of $\mathrm{NiO}$ were grown on nickel foam and also functionalised with 12-crown-4 a selective zinc ion ionophore. The as-grown $\mathrm{NiO}$ nanostructures exhibited good crystal quality and have shown a good potentiometric response in the development of a zinc ion-selective electrode. The $\mathrm{NiO}$ nanostructures-based zinc ion sensor electrode detected a wide linear range of zinc ion concentrations from $0.001 \mathrm{mM}$ to $100 \mathrm{mM}$ with a low limit of detection of $0.0005 \mathrm{mM}$. The sensitivity of the proposed zinc ion sensor was found to be of $36 \mathrm{mV} / \mathrm{decade}$ and the regression coefficient 0.99 . Beside these characteristics, the zinc ion sensor electrode demonstrated good reproducibility, repeatability, and selectivity, a fast response time of less than $10 \mathrm{~s}$ and good storage stability. The zinc ion sensor electrode was also used as indicator electrode in potentiometric titrations. All the obtained results indicated that the proposed zinc ion sensor electrode has good potential for analysing zinc ions in industrial, clinical and other real samples. 


\section{References}

1. Berg, J.M.; Shi, Y. The galvanization of biology: A growing appreciation for the roles of zinc. Science 1996, 271, 1081-1085.

2. Paker, M.M.; Humaller, F.L.; Mahler, D.J. Determination of copper and zinc in biological material. Clin. Chem. 1967, 13, 40-48.

3. Vallee, B.L.; Falchuk, K.H. The biochemical basis of zinc physiology. Physiol. Rev. 1993, 73, 79-118.

4. Frederickson, C.J. Neurobiology of zinc and zinc-containing neurons. Int. Rev. Neurobiol. 1989, $31,145-243$.

5. Zalewski, P.D.; Millard, S.H.; Forbes, I.J.; Kapaniris, O.; Slavotinek, A.; Betts, W.H.; Ward, A.D.; Lincoln, S.F.; Mahadevan, I. Video image analysis of labile zinc in viable pancreatic islet cells using a specific fluorescent probe for zinc. J. Histochem. Cytochem. 1994, 42, 877-884.

6. Zalewski, P.D.; Jian, X.; Soon, L.L.; Breed, W.G.; Seamark, R.F.; Lincoln, S.F.; Ward, A.D.; Sun, F.Z. Changes in distribution of lablic zinc in mouse spermatozoa during maturation in the epididymis assessed by the flourophore zinquin. Reprod. Fertil. Dev. 1996, 8, 1097-1105.

7. Truong-Tran, A.Q.; Ho, L.H.; Chai, F.; Zalewski, P.D. Cellular zinc fluxes and the regulation of apoptosis/gene-directed cell death. J. Nutr. 2000, 130, 1459-1466.

8. Choi, D.W.; Koh, J.Y. Zinc and brain injury. Annu. Rev. Neurosci. 1998, 21, 347-375.

9. Frederickson, C.J.; Hernandez, M.D.; McGinty, J.F. Translocation of zinc may contribute to seizure-induced death of neurons. Brain Res. 1989, 480, 317-321.

10. Koh, J.Y.; Suh, S.W.; Gwag, B.J.; He, Y.Y.; Hsu, C.Y.; Choi, D.W. The role of zinc accumulation and cell death after transient global cerebral ischemia. Science 1996, 272, 1013-1016.

11. Bush, A.I.; Pettingell, W.H.; Multhaup, G.; Paradis, M.D.; Vonsattel, J.P.; Gusella, J.F.; Beyreuther, K.; Masters, C.L.; Tanzi, R.E. Rapid induction of Alzhemimer A beta amyloid formation by zinc. Science 1994, 265, 1464-1467.

12. Voegelin, A.; Pfister, S.; Scheinost, A.C.; Marcus, M.A.; Kretzschmar, R. Changes in zinc speciation in field soil after contamination with zinc oxide. Environ. Sci. Technol. 2005, 39, 6616-6623.

13. Mertens, J.; Degryse, F.; Springael, D.; Smolders, E. Zinc toxicity to nitrification in soil and soilless culture can be predicted with the same biotic ligand model. Environ. Sci. Technol. 2007, 41, 2992-2997.

14. Callender, E.; Rice, K.C. The urban environmental gradient: Anthropogenic influences on the spatial and temporal distributions of lead and zinc in sediments. Environ. Sci. Technol. 2000, 34, 232-234.

15. Kaur, P.; Kaur, S.; Mahajan, A.; Singh, K. Highly selective colorimetric sensor for $\mathrm{Zn}^{2+}$ based on hetarylazo derivative. Inorg. Chem. Commun. 2008, 11, 626-629.

16. Gupta, N.R.; Mittal, S.; Kumar, S.; Kumar, S.K.A. Potentiometric studies of $N, N^{\prime}$-Bis(2-dimethylaminoethyl)- $N, N^{\prime}$-dimethyl-9,10 anthracenedimethanamine as a chemical sensing material for Zn(II) ions. Mater. Sci. Eng. C 2008, 28, 1025-1030. 
17. Li, Q.; Zhao, X.H.; Lv, Q.Z.; Liu, G.G. The determination of zinc in water by flame atomic absorption spectrometry after its separation and preconcentration by malachite green loaded microcrystalline triphenylmethane. Sep. Purif. Technol. 2007, 55, 76-81.

18. Wilhartitz, P.; Dreer, S.; Krismer, R.; Bobleter, O. High performance ultra-trace analysis in molybdenum and tungsten accomplished by on-line coupling of ion chromatography with simultaneous ICP-AES. Microchim. Acta 1997, 125, 45-52.

19. Hosseini, M.; Vaezi, Z.; Ganjali, M.R.; Faridbod, F.; Abkenar, S.D.; Alizadeh, K.; Salavati-Niasari, M. Fluorescence "turn-on" chemosensor for the selective detection of zinc ion based on Schiff-base derivative. Spectrochim. Acta A 2010, 75, 978-982.

20. Ma, Q.J.; Zhang, X.B.; Zhao, Y.; Li, C.Y.; Han, Z.X.; Shen, G.L.; Yu, R.Q. A fluorescent probe for zinc ions based on $N$-methyltetraphenyprophine with high selectivity. Spectrochim. Acta A 2009, 71, 1683-1687.

21. Gupta, V.K.; Agarwal, S.; Jakob, A.; Lang, H. A zinc-selective electrode based on $N, N^{\prime}$-bis(acetylacetone)ethylenediimine. Sens. Actuators B 2006, 114, 812-818.

22. Fakari, A.R.; Alaghemand, M.; Shamsipur, M. Zinc-selective membrane electrode based on 5,6,14,15-Dibenzo-1,4-Dioxa-8,12-Diazacyclopentadecane-5,14-Diene. Anal. Lett. 2000, 33, 2169-2181.

23. Singh, A.K.; Jain, A.K.; Saxena, P.; Mehtab, S. Zn(II)-selective membrane electrode based on tetraazamacrocycle $\left[\mathrm{Bzo}_{2} \mathrm{Me}_{2} \mathrm{Ph}_{2}(16)\right.$ hexaeneN 4 ]. Electroanalysis 2006, 18, 1186-1192.

24. Gupta, V.K.; Jain, A.K.; Mangla, R.; Kumar, P. A new $\mathrm{Zn}^{2+}$-selective sensor based on 5,10,15,20-tetraphenyl-21H,23H-porphine in PVC matrix. Electroanalysis 2001, 13, 1036-1040.

25. Shamsipur, M.; Rouhani, S.; Ganjali, M.R.; Sharghi, H.; Eshghi, H. Zinc-selective membrane potentiometric sensor based on a recently synthesized benzo-substituted macrocyclic diamide. Sens. Actuators B 1999, 59, 30-34.

26. Ganjali, M.R.; Zamani, H.A.; Norouzi, P.; Adib, M.; Rezapour, M.; Aceedy, M. Zn ${ }^{2+}$ PVC-based membrane sensor based on 3-[(2-Furylmethylene)amino]-2-thioxo-1,3-thiazolidin-4-one. Bull. Kor. Chem. Soc. 2005, 26, 579-584.

27. Hosseini, M.; Sadeghi, H.B.; Rahimi, M.; Salavati-Niasari, M.; Abkenar, S.D.; Alizadeh, K.; Ganjali, M.R. Highly selective and sensitive tin(II) membrane electrode based on a new synthesized Schiff's base. Electroanalysis 2009, 21, 859-866.

28. Ganjali, M.R.; Ghesmi, A.; Hosseini, M.; Pourjavid, M.R.; Rezapour, M.; Shamsipur, M.; Salavati-Niasari, M. Novel terbium(III) sensor based on a new bis-pyrrolidene Schiff's base. Sens. Actuators B 2005, 105, 334-339.

29. Ganjali, M.R.; Ravanshad, J.; Hosseini, M.; Salavati-Niasari, M.; Pourjavid, M.R.; Baezzat, M.R. Novel Dy(III) sensor based on a new bis-pyrrolidene Schiff's base. Electroanalysis 2004, 16, 1771-1776.

30. Hosseini, M.; Rahimi, M.; Bagheri Sadeghi, H.; Taghvaei-Ganjali, S.; Dehghan Abkenar, S.; Ganjali, M.R. Determination of $\mathrm{Hg}(\mathrm{II})$ ions in water samples by a novel $\mathrm{Hg}$ (II) sensor, based on calix[4]arene derivative. Int. J. Environ. Anal. Chem. 2009, 89, 407-422.

31. Poursaberi, T.; Hosseini, M.; Taghizadeh, M.; Pirelahi, H.; Shamsipur, M.; Ganjali, M.R. A selective membrane electrode for iodide ion based on a thiopyrilium ion derivative as a new ionophore. Microchem. J. 2002, 72, 77-83. 
32. Ibupoto, Z.H.; Ali, S.M.U.; Chey, C.O.; Khun, K.; Nur, O.; Willander, M. Selective zinc ion detection by functionalised $\mathrm{ZnO}$ nanorods with ionophore. J. Appl. Phys. 2011, 110, 104702-104707.

33. Hosseini, M.; Dehghan Abkenar, S.; Ganjali, M.R.; Faridbod, F. Determination of zinc(II) ions in waste water samples by a novel zinc sensor based on a new synthesized Schiff's base. Mater. Sci. Eng. C 2011, 31, 428-433.

34. Chantrell, R.W.; O’Grady, K. Applied Magnetism; Gerber, R., Wright, C.D., Asti, G., Ed.; Kulwer Academic Publishers: Dordrecht, The Netherlands, 1994; p. 113.

35. Gleiter, H. Nanostructured materials: Basic concepts and microstructure. Acta Mater. 2000, 48, 1-29.

36. Feldman, C.; Jungk, H.O. Polyol-mediated preparation of nanoscale oxide particles. Angew. Chem. Int. Ed. 2001, 40, 359-362.

37. Biji, V.; Khadar, M.A. Analysis of AC electrical properties of nanocrystalline nickel oxide. Mater. Sci. Eng. A 2011, 304, 814-817.

38. Yang, H.; Tao, Q.; Zhang, X.; Tang, A.; Ouyang, J. Solid-state synthesis and electrochemical property of $\mathrm{SnO}_{2} / \mathrm{NiO}$ nanomaterials. J. Alloy. Compounds 2008, 459, 98-102.

39. Xuping, Z.; Guoping, C. The microstructure and electrochromic properties of nickel oxide films deposited with different substrate temperatures. Thin Solid Films 1997, 298, 53-56.

40. Zhang, P.; Zuo, F.; Urban, F.K., III; Khabari, A.; Griffiths, P.; Tehrani, A.H. Irreversible magnetization in nickel nanoparticles. J. Magn. Magn. Mater. 2001, 225, 337-345.

41. Bouessay, I.; Rougier, A.; Poizot, P.; Moscovici, J.; Michalowicz, A.; Tarascon, J.M. Electrochromic degradation in nickel oxide thin film: A self-discharge and dissolution phenomenon. Electrochim. Acta 2005, 50, 3737-3745.

42. Sumikura, S.; Mori, S.; Shimizu, S.; Usami, H.; Suzuki, E. Syntheses of NiO nanoporousfilms using nonionic triblock co-polymer templates and their application to photo-cathodes of p-type dye-sensitized solar cells. J. Photochem. Photobiol. A Chem. 2008, 199, 1-7.

43. Zayim, E.O.; Turhan, I.; Tepehan, F.Z.; Ozer, N. Sol-gel deposited nickel oxide films for electrochromic applications. Sol. Energ. Mat. Sol. C 2008, 92, 164-169.

44. Hotovy, I.; Huran, J.; Spiess, L.; Hascik, S.; Rehacek, V. Preparation of nickel oxide thin films for gas sensors applications. Sens. Actuators B 1999, 57, 147-152.

45. Gaspera, E.D.; Buso, D.; Guglielmi, M.; Martucci, A.; Bello, V.; Mattei, G.; Post, M.L.; Cantalini, C.; Agnoli, S.; Granozzi, G.; Sadek, A.Z.; Kalantar-zadeh, K.; Wlodarski, W. Comparison study of conductometric, optical and SAW gas sensors based on porous sol-gel silica films doped with NiO and Au nanocrystals. Sens. Actuators B 2010, 143, 567-573.

46. Porqueras, I.; Bertran, E. Electrochromic behaviour of nickel oxide thin films deposited by thermal evaporation. Thin Solid Films 2001, 398, 41-44.

47. Chen, H.L.; Lu Y.M.; Hwang, W.S. Characterization of sputtered NiO thin films. Surf. Coat. Technol. 2005, 198, 138-142.

48. Lenggoro, I.W.; Itoh, Y.; Iida, N.; Okuyama, K. Control of size and morphology in NiO particles prepared by a low-pressure spray pyrolysis. Mater. Res. Bull. 2003, 38, 1819-1827.

49. Wu, Y.; He, Y.; Wu, T.; Weng, W.; Wan, H. Effect of synthesis method on the physical and catalytic property of nanosized NiO. Mater. Lett. 2007, 61, 2679-2682. 
50. Hamid, M.A.A.; Bakar, M.A.; Jalar, A.; Shamsudin, R.; Ahmad, I. Morphology and optical properties of nickel oxide nanostructure from aqueous solution. Adv. Mat. Res. 2012, 399-401, 581-584.

51. Shah, M.A. A versatile route for the synthesis of nickel oxide nanostructures without organics at low temperature. Nanoscale Res. Lett. 2008, 3, 255-259.

51. Wang, H.X.; Pu, M. A porphyrin based potentiometric sensor for zinc determination. Chin. Chem. Lett. 2002, 13, 355-358.

53. Gupta, V.K.; Chauhan, D.K.; Saini, V.K.; Agarwal, S.; Antonijevic, M.M.; Lang, H. A prophyrin based potentiometric sensor for zinc determination. Sensors 2003, 3, 223-235.

54. Gupta, V.K. A PVC-based 12-crown-4 membrane potentiometric sensor for zinc(II) ions. Sens. Actuators B 1999, 55, 195-200.

55. Gupta, V.K.; Jain, A.K.; Maheshwari, G. A new $\mathrm{Zn}^{2+}$-selective potentiometric sensor based on dithizone-PVC membrane. Chem. Anal. 2006, 51, 889-897.

(C) 2012 by the authors; licensee MDPI, Basel, Switzerland. This article is an open access article distributed under the terms and conditions of the Creative Commons Attribution license (http://creativecommons.org/licenses/by/3.0/). 